\title{
Planning, crime and urban sustainability
}

\author{
P. Cozens \\ Curtin University of Technology, Western Australia
}

\begin{abstract}
Globally, the environmental movement has played a pivotal role in influencing the development of sustainability. Increasingly, urban sustainability is seen as a new large-scale vision to guide the planning agenda for the twenty-first century. However, a review of the literature clearly indicates that crime and fear of crime can seriously undermine the broader aims of urban sustainability. Furthermore, analysts tend to focus on levels of recorded crime, largely ignoring the crucial and arguably more important dimension of citizens' fear of crime and their perceptions of their local environment. This paper provides recommendations for integrating crime and fear of crime within urban sustainability. It also proposes that 'designing out crime' represents a vital tool for assisting in the development of urban sustainability.
\end{abstract}

Keywords: urban sustainability, crime and fear of crime, designing out crime, Crime Prevention Through Environmental Design (CPTED).

\section{Introduction}

Cities have many impacts on the environment and upon its inhabitants, both in contemporary terms and for future generations. However, if sustainability is to adequately represent the new large-scale vision to guide the planning agenda for the twenty-first century [1] it must incorporate a consideration for all potential threats to the long-term sustainable health and vitality and personal safety of both the built environment and of its occupants. This paper discusses a threat to long-term sustainability, which can seriously challenge the city's functioning, vitality and longevity. The ubiquitous issues of crime and the fear of crime are included within some sustainability frameworks, but arguably need to be explicitly integrated. Analysts tend to focus on levels of recorded crime, largely ignoring the crucial and arguably more important dimension, of citizens' fear of crime and perceptions of their local environment. 
It is also proposed that Designing Out Crime, also known as CPTED (Crime Prevention Through Environmental Design) represents a useful tool for assisting in the creation of more efficient and sustainable urban design protocols. Designing Out Crime has emerged in recent years as a socio-spatial perspective within both criminology and urban planning [2,3]. It is defined by Crowe [4, p1] as; "the proper design and effective use of the built environment [which] can lead to a reduction in the fear of crime and the incidence of crime, and to an improvement in the quality of life". Designing Out Crime builds upon four key strategies of territoriality, natural surveillance, activity support and access control in order to maximise the self-policing potential of the community. It promotes higher densities, mixed-use development and activities, which optimise the number of potential "eyes on the street" [5]. Designing Out Crime also promotes the effective and continuous maintenance and management of urban space and discourages the under-use of such space [6]. Research has reported positive reductions to levels of recorded crime in the UK [7] and more recently a major review of Designing Out Crime firmly demonstrates its efficacy as a crime prevention strategy $[3,7,8]$.

\section{Urbanism, security and sustainability}

The organisation of human settlements has always sought to provide for the safety, security and the well-being of their residents in terms of design and location close to water, food and other vital resources. From early prehistoric cave-dwellers to medieval and modern cities, safety and security have been central issues. As technology changed, settlements adapted to reflect new and emerging threats. For example, a variety of fortification designs for castles such as landscaping, protective walls, and moats occurred throughout the middle ages and thereafter. 'Others', assumed to exist beyond such perimeters, represented the threats to such communities in the form of the threat of attack, plunder and war. Intriguingly, Bronowski [9] has referred to war as a highly planned form of theft.

Industrialisation and urbanisation created a range of new threats to public health and well-being. The rapid, unplanned and 'laissez faire' expansion of cities resulted in overcrowding, pollution, poverty, disease, crime and 'anomie' [10] with cities becoming containers of problems as well as places of vitality, excitement and 'joie de vivre'. $19^{\text {th }}$ century commentators, such as Mayhew [11] and Booth [12] among others, made causal connections between crime and areas with poor economic, social and environmental performance. Some were dismayed and shocked at the condition of cities and various 'philanthropic' visions, developments and model urbanisations were designed (e.g. Robert Owen's New Lanark, 1799; Titus Salt's Saltaire, 1853; George Cadbury's Bourneville, 1890 and Ebenezer Howard's Garden City movement, 1898).

Arguably, the public health era was the first attempt at a version of what might be termed sustainable 'planning'. Indeed, Carmona [13] asserts that notions of local, social and economic sustainability can be traced back to the pioneers of the town planning movement such as Howard, Geddes and Unwin. 
However, he argues that recent writings on the concept have firmly shifted towards broader environmental concerns. Many conceptualizations of sustainability are underpinned by notions of social sustainability; equity, opportunity, quality of life and participation. Indeed, Yiftachel and Hedgcock [15] discuss the concept of 'urban social sustainability' arguing it is about meeting the social needs of present and future generations - and a safe and secure environment is certainly one of these needs. More recently, Porta and Renne [14] have recently developed urban fabric and street indicators for sustainability, which attempt to quantify urban design. However, few, if any, have developed operational strategies to measure or combat crime and the fear of crime. In terms of human needs, Maslow's [16] hierarchy suggests sustainable environments should cater for physiological, safety and security, affiliation (belonging and acceptance), esteem (status) and self-actualisation (expression and fulfilment) needs - in that order. For Carmona [13] the human needs principle within sustainability should allow "...safe and crime-free human contact" [13, p167].

Globally, the environmental movement has played a pivotal role in influencing the development of sustainability and in WA is defined as; "Meeting the needs of current and future generations through an integration of environmental protection, social advancement and economic prosperity" [17, p12]. However, in common with many models, references to crime and fear of crime are implicit, rather than explicit and there is little information concerning crime or fear of crime as indicators for sustainability and how these two issues might be measured. Despite diverse viewpoints on the essential criteria for sustainability, there are several recurring themes including identify inclusivity, connectivity, equity, prudence and security. Indeed, Black [18, p8] notes; "security is an integral part of sustainability, and it is generally essential if people are to achieve their full potential."

\section{Crime and sustainability}

Sustainability will not achieve its full potential unless it explicitly includes measures to address the ubiquitous problems of crime and the fear of crime within the community. Indeed, Du Plessis [19, p33] argues "no city can call itself sustainable if the citizens of that city fear for their personal safety and the safety of their livelihood". Significantly, studies have repeatedly found that safety and security are often the first priority of the urban poor in both developed and developing countries [20].

In Australia, the financial costs of crime to the community have been estimated to be around $\$ 32$ billion [21] per annum although personal, psychological and emotional costs are clearly omitted. These costs include A $\$ 12.75$ million in tackling crime and costs to the community of around A $\$ 19$ million. Urban design could be potentially implicated in some of these areas including burglary and theft of vehicles estimated to cost $\$ 2.4$ billion and $\$ 880$ million per annum respectively. Assault accounts for around $\$ 1.44$ billion while robbery in Australia costs some $\$ 600$ million per annum [21]. The costs of fear 
of crime have not been evaluated although studies reveal that significant sections of the community are fearful for their personal safety when using or visiting the city. For example in a survey of seven thousand respondents, $26 \%$ reported that they felt unsafe while walking after dark in their own neighbourhood [22] and this figure increases significantly for more vulnerable groups such as women and the elderly. Furthermore, fear of crime increases after dark for all user groups. There are also those who do not use the city at certain times and some who may not use it at all.

A city is an ecosystem [23] and withn the city, crime and the fear of crime are interwoven within this ecosystem. The study of both environmental criminology and the 'ecology of crime' arguably warrant consideration as a central component of urban sustainability. As early as the 1920s, Park et al., [24], Burgess [25] and other urban sociologists of the 'Chicago School of Human Ecology', proposed that there were interesting comparisons between the natural distribution of plant life and the organisation of human life. The ecology of crime is an important dimension and which has recently been re-examined. In Crime and Nature, Felson [26] analyses crime in terms of its ecosystem, setting, habitat, and niches as well as discussing crime competition, adaption, symbiosis, mutualism and parasitism.

Thirty years ago Herbert [27, p208] wrote "as a geographical paradigm, environmentalism might have provided the most logical link to a geography of crime. That it did not do so was in part a function of scale, but more particularly of its view of the natural environment as the habitat of man". Significantly, the situation remains unchanged, in spite of the fact that $90 \%$ of the population in WA resides in 'urban' areas [17]. Crucially, crime is more prevalent and concentrated in urban areas.

Sustainability has been predominantly perceived as an environmental or economic issue [19, 28], which fails to consider the issues of crime and fear of crime to any meaningful extent while others have discussed the subject minimally [29]. Indeed, crime as a dimension of sustainability has only recently been subject to more widespread evaluation and discussion $[19,28]$ and arguably represents a dynamic addition to this evolving body of knowledge. The organic nature and our current understanding of sustainability means that the indicators are not fixed and need to continually respond to changing circumstances, especially and as our knowledge develops. A consideration of Designing Out Crime strategies certainly constitutes a positive development of knowledge in this regard. A prerequisite for a sustainable urban environment is that it should not pose a threat to current or future users. Indeed, Dewberry [30] argues that there are various synergies between sustainability and crime prevention (see Table 1).

Although many examples of attempts at 'ecologically sustainable design' (ESD) developments exist, few have evolved beyond developing mainly environmental goals. Such a focus is predominantly upon maximising efficiencies for building materials, transport, energy and water, while reducing pollution, waste, noise and impacts on the ecological diversity of the natural environment using 'whole of life thinking' for any development [31]. 
Significantly, the 'Smart Housing' initiative in Queensland, Australia is an exception and attempts to integrate ESD, Designing Out Crime and universal design principles [32], although others argue there may be some conflicts between designing out crime and ecological sustainability [33] that need to be researched and, if necessary, resolved.

Table 1: $\quad$ Synergies between sustainability and crime prevention [30].

\begin{tabular}{|l|l|}
\hline Crime Prevention & Sustainability \\
\hline Shared responsibility for crime & Shared responsibility for sustainability \\
\hline Offenders to acknowledge responsibility & Polluters to acknowledge responsibility \\
\hline Crime events promote social exclusion & Inequity in the security of communities \\
\hline $\begin{array}{l}\text { Reducing effects of crime through } \\
\text { investment in evidence and effectiveness }\end{array}$ & $\begin{array}{l}\text { Reducing environmental impacts through } \\
\text { investment in evidence and effectiveness }\end{array}$ \\
\hline $\begin{array}{l}\text { Reducing the impacts of crime through } \\
\text { developing products and systems which } \\
\text { are more resistant to criminal activity }\end{array}$ & $\begin{array}{l}\text { Promoting sustainability by developing } \\
\text { products and systems which are more } \\
\text { environmentally and socially responsible }\end{array}$ \\
\hline $\begin{array}{l}\text { The need for government strategies } \\
\text { partnerships, evidence-based action and } \\
\text { accountability }\end{array}$ & $\begin{array}{l}\text { The need for government strategies, } \\
\text { partnerships, best practice and } \\
\text { environmental and social responsibility }\end{array}$ \\
\hline Promoting quality of life issues & Understanding quality of life issues \\
\hline $\begin{array}{l}\text { Enhancing understanding of the ecology } \\
\text { of crime and environmental criminology }\end{array}$ & $\begin{array}{l}\text { Enhancing understanding of the ecology of } \\
\text { the environment }\end{array}$ \\
\hline $\begin{array}{l}\text { Use of the built environment to reduce } \\
\text { opportunities for crime and promote } \\
\text { liveability }\end{array}$ & $\begin{array}{l}\text { Use of the built environment to reduce } \\
\text { waste and promote liveability and } \\
\text { sustainability }\end{array}$ \\
\hline
\end{tabular}

Developing and measuring indicators for sustainability is clearly challenging and accurately measuring crime is certainly problematic. Relying on officially derived crime statistics for the purpose of measuring sustainability could undermine its effectiveness and it should arguably include indicators for fear of crime and the perceptions of different user groups within the community. The Australian Bureau of Statistics [22] estimates that the under-reporting of official crime statistics varies considerably in terms of specific crime types, further reducing the efficacy of using one generic indicator for 'crime' as part of a sustainability protocol. For example, in a study in Australia, $74 \%$ reported being victims of break-ins while only $31 \%$ of victims of assault reported the most recent incident to police [22]. Furthermore, researchers [34] have discussed the idea that fear of crime may exist in areas, which according to official statistics, are 'safe'. Crucially, crime statistics may represent only a fraction of total crime with the missing data simply referred to as the 'dark figure of crime' [35].

Brantingham and Brantingham [36] argue environmental criminology should be more explicitly considered within planning stating "most planning proceeds with little knowledge of crime patterns, crime attractors, crime generators, the importance of edges, paths and nodes or the site specific conditions that facilitate or even encourage crime" [36, p53]. 


\section{Conclusion}

In spite of the diverse interpretations and multiple definitions of sustainability Berke [1, p35] asserts that the concept; "has been touted as the new large-scale vision to guide the planning agenda for the twenty-first century". However, in order for it to progress beyond a vague idealism it must translate theory into practice. Failure to do this would arguably limit sustainability to a futuristic utopian vision in the mould of Thomas More's Utopia [37], impractical and unachievable.

In Australia, the national commitment to Designing Out Crime is arguably one example whereby the precautionary principle is being implemented from theory into practice. In WA, housing projections for 2031 estimate 375,000 new homes will be required [17] and that most (60\%) will be built in existing urban areas (the potential for evaluating the sustainability of new-build housing has been discussed elsewhere [38]). The publication of Designing Out Crime Planning Guidelines supported by Planning Bulletin No.79 [39, 40] and a State Designing Out Crime Strategy to embed such ideas within the planning process clearly represents a commitment to development that will meet present needs and acknowledges the needs of future generations.

Furthermore, a recent report by the Parliament of the Commonwealth of Australia, entitled, Sustainable Cities [41] recognises Designing Out Crime a useful approach to building communities. In WA various regulations relating to the built environment exist to protect public health and safety (including fire regulations), to encourage energy efficiency; reduce waste and pollution and, more recently, to promote disabled access. Amendments to the Building Code of Australia now ensure that all new housing will be required to meet five-star energy ratings. Notably, the potential impact on crime and the fear of crime are $\underline{\text { not }}$ part of this assessment process.

Internationally, it is arguable that sustainability frameworks do not currently include adequate consideration for the potential impacts on crime and the fear of crime of new or existing urban developments. Furthermore, crime and the fear of crime have the potential to erode and reduce existing levels of sustainability within a community. In conclusion, a sustainable community must be one that is defined as safe, perceives itself to be safe and is widely considered by others to be safe. Urban sustainability must therefore include more explicitly measures for crime(s) and the fear of crime. Indicators for 'crime' should be crime-type specific, rather than a generic aggregation of all incidents of crime. The embedding of Designing Out Crime concepts in building regulations, the building code of Australia and national and state planning policy frameworks should hopefully go someway towards avoiding the repetition of some of the 'unsustainable' design failures of the recent past. Indeed, as Du Plessis [19, p33] argues "environmental design modifications aimed at creating safer communities in many cases also address the socio-economic requirements for more sustainable settlements, and the solutions complement each other".

The application of Designing Out Crime in isolation will not necessarily contribute significantly towards the wider objectives of sustainability protocols. 
Similarly, at present, sustainability is unlikely to have any tangible impact upon levels of crime or the fear of crime. However, reducing opportunities for crime, poor health, disease and environmental degradation are all outcomes that can be achieved by the development of a more holistic form of urban sustainability. Crime is predominantly urban and is highly complex and dynamic. However, Du Plessis [19, p38] argues that although environmental design (in isolation) does not represent the solution to the problem of crime or to guarantee that a city is sustainable, it can "create a supportive physical environment for social and economic initiatives".

Arguably, a form of urban sustainability that incorporates indicators of crimes and fear of crime as well as integrating Designing Out Crime measures, will more effectively meet the needs of present and future generations. This inclusion will ensure that architects, designers, planners and developers shape the environment appropriately while also designing out crime and designing $\underline{\text { in }}$ people. Australian and global sustainability protocols for urban design will therefore potentially be more robust, holistic and relevant in an increasingly urbanised world.

\subsection{Recommendations for the development of urban sustainability}

- Conduct research into various urban design principles which may work elsewhere, and which are assumed to work in WA and Australia such as New Urbanism and the principles of walkability and permeability.

- Utilise disaggregated data to analyse recorded crime at the local level and analyse specific crime-types rather than a generic category of 'crime'.

- Develop and utilise measures of fear of crime and people's perceptions of crime at the local level and analyse specific crime-types rather than a generic category of 'crime'.

- Experiment with Designing Out Crime strategies synergistically in urban developments that have conducted environmental impact assessments, ESD projects and those that employ ecologically sustainable city designs.

- Use measures of crime and fear of crime as integral components and key indicators of sustainability.

- Critically evaluate Designing Out Crime as a tool for delivering more sustainable urban communities.

- Develop crime prevention and security rating indices for buildings and developments and integrate these into existing and developing processes for 'building sustainability' and 'green star' certification.

- Research potential areas of conflict between ecological sustainability and Designing Out Crime and develop procedures to limit or address them.

\section{References}

[1] Berke, J., Does Sustainable Development Offer a New Direction for Planning? Challenges for the Twenty-First Century. Journal of Planning Literature, 17(1), pp. 21-36, 2002. 
[2] Cozens, P., Hillier, D. and Prescott, G., Crime and the Design of Residential Property. Exploring the Theoretical Background. Property Management, 19(2), pp. 136-164, 2001.

[3] Cozens, P., Saville, G. and Hillier, D., Crime Prevention Through Environmental Design (CPTED): A Review and Modern Bibliography. Journal of Property Management, 23(5), pp. 328-356, 2005.

[4] Crowe, T., Crime Prevention Through Environmental Design: Applications of Architectural Design and Space Management Concepts ( $2^{\text {nd }}$ Edition). Butterworth-Heinemann: Oxford, 2000.

[5] Jacobs, J., The Death and Life of Great American Cities. Vintage Books: New York, 1961.

[6] Wilson, J. and Kelling, G., The Police and Neighbourhood Safety. 'Broken Windows'. The Atlantic Monthly, 3, pp. 29-38, 1982.

[7] Cozens, P., Pascoe, T. and Hillier, D., The Policy and Practice of Secured By Design (SBD). Crime Prevention and Community Safety: An International Journal, 6(1), pp. 13-29, 2004.

[8] Cozens, P., Designing Out Crime - From Evidence to Action. Delivering Crime Prevention: Making the Evidence Work. Australian Institute of Criminology and the New South Wales Attorney-General's Department. Carlton Crest Hotel, Sydney, 21-22 November 2005. http://www.aic.gov.au/conferences/2005-cp/cozens.html

[9] Bronowski, J., The Ascent of Man. Little Brown \& Co, BBC Books: London, 1974.

[10] Wirth, L. Urbanism as a Way of Life. The American Journal of Sociology, 44,(1), pp. 1-24, 1938.

[11] Mayhew, H., London Labour and the Condition of the London Poor. Griffin: Bohn, London, 1862.

[12] Booth, C., Labour and Life of the People. Williams and Norgate: London, 1889.

[13] Carmona, M., Sustainable Urban Design - A Possible Agenda, In (eds.) Layard, A., Davoudi, S., and Batty, S., Planning for a Sustainable Future. Spon Press: London, pp. 165-192, 2001.

[14] Porta, S. and Renne, J., Linking Urban Design to Sustainability: Formal Indicators of Social Urban Sustainability Field Research in Perth, Western Australia. Urban Design International, 10, pp. 51-64, 2005.

[15] Yiftachel, O. and Hedgcock, D., Urban Social Sustainability. The Planning of an Australian City. Cities: The International Journal of Urban Policy and Planning, 10(2), pp139-157, 1993.

[16] Maslow, A., Motivation and Personality. Harper: New York, 1943.

[17] Government of Western Australia, Hope for the Future: The Western Australian State Sustainability Strategy. Department of Premier and Cabinet: Perth, 2003.

[18] Black, A., The Quest for Sustainable Healthy Communities. Paper presented at the Effective Sustainability Education: What Works? Why? Where Next? Linking Research and Practice Conference, Sydney, Australia, 18-20 $0^{\text {th }}$ February, 2004. 
[19] Du Plessis, C., The Links Between Crime Prevention and Sustainable Development. Open House International, 24(1), pp. 33-40, 1999.

[20] Napier, M., Du Plessis, C. Liebermann, S., Kruger, T., Shaw, M., Louw, A. and Oppler, S., Environmental Design for Safer Communities in South Africa, 1 and 2, Council for Scientific and Industrial Research: Pretoria, 1998.

[21] Mayhew, P., Counting the Costs of Crime in Australia. Australian Institute of Criminology (AIC), Trends and Issues No. 247, AIC, Canberra, 2003.

[22] Johnson, H., Crime Victimisation in Australia: Key Results of the 2004 International Crime Victimisation Survey. Research and Public Policy Series, No. 64, 2005.

[23] Grimm, N., Grove, J., Picket, S., and Redman, C., Integrated Approaches to Long-term Studies of Urban Ecological Systems. Bioscience, 50(7), pp. 571-584, 2000.

[24] Park, R., Burgess E. and McKenzie, D., The City. University of Chicago Press: Chicago, 1925.

[25] Burgess, E., The Growth of the City. In Park, R.E., Burgess, E.W. and McKenzie, D. (Eds). The City. University Press: Chicago, 1925.

[26] Felson, M., Crime and Nature. Sage Publications: Thousand Oaks, California, 2006.

[27] Herbert, D., Crime Delinquency and the Urban Environment. Progress in Human Geography. 1, pp208-239, 1977.

[28] Cozens, P., Sustainable Urban Development and Crime Prevention Through Environmental Design for the British City; Towards an Effective Urban Environmentalism for the 21st Century. Cities: The International Journal of Urban Policy and Planning, 19(2), pp. 129-137, 2002.

[29] Goodchild, B., Housing Design. Urban Form and Sustainable Development. Town Planning Review, 2(65), pp143-158, 1994.

[30] Dewberry, E., Designing Out Crime: Insights from Eco-design. Security Journal 16, pp. 51-62, 2003.

[31] Australian Government, ESD Design Guide for Australian Government Buildings, Department of Environment and Heritage. Canberra, 2006.

[32] Queensland Department of Housing. Research House: Towards Healthy and Sustainable Housing Research Project: Queensland Government. Online http:www.housing.qld.gov.au/builders/research house/index.htm. 2004.

[33] Sarkissian Associates Planners, Australian Capital Territory's Crime Prevention and Urban Design Resource Manual. Department of Urban Services: Canberra, Australia 2000.

[34] Nasar, J., and Fisher, B., 'Hot Spots' of Fear and Crime: A Multi-method Investigation. Journal of Environmental Psychology, 13, pp. 187-206, 1993.

[35] Scott, J., A Matter of Record. Polity Press and Basil Blackwell Inc. 1990. 
[36] Brantingham, P. and Brantingham, P., Environmental Criminology: From Theory to Urban Planning Practice. Studies on Crime and Crime Prevention, 7(1), pp. 31-60, 1998.

[37] More, T. Utopia. Louvain: France, 1516.

[38] Cozens, P., Hillier, D. and Prescott, G., The Sustainable and the Criminogenic. The Case for New-Build Housing Projects in Britain. Property Management, 17(3), pp. 252-261, 1999.

[39] Western Australian Planning Commission (WAPC), Designing Out Crime Guidelines. WAPC: Perth, Western Australian, 2006a. Online. http://www.wapc.wa.gov.au.

[40] Western Australian Planning Commission (WAPC), Designing Out Crime Planning Bulletin No.79. WAPC, Perth, Western Australian, $2006 \mathrm{~b}$. Online. www.wapc.wa.gov.au.

[41] The Parliament of the Commonwealth of Australia, Sustainable Cities, House of Representatives Standing Committee on Environment and Heritage, Canberra, Australia. Online http://www.aph.gov.au/house/ committee/environ/cities/report.htm. 